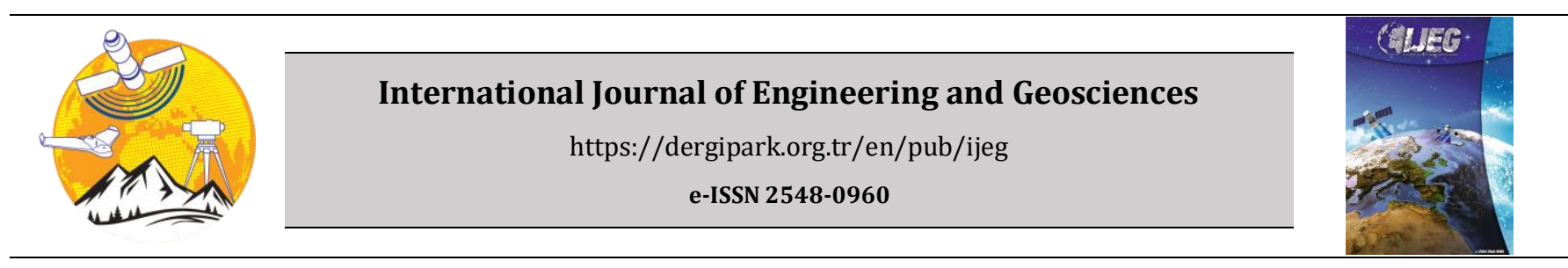

\title{
Change detection and future change prediction in Habra I and II block using remote sensing and GIS - A case study
}

\author{
Swapan Paul ${ }^{*}$ \\ ${ }^{1}$ West Bengal State University, Department of Geography, Kolkata, India
}

\author{
Keywords \\ Change detection \\ Urban Expansion \\ Hotspot/Coldspot \\ Change prediction \\ Cellular automata
}

\begin{abstract}
Mapping, analysis, and monitoring of landuse and landcover in micro region is necessary for sustainable land development, planning and management. The present study is, therefore, aimed to identify the spatio-temporal change of LULC in two central administrative C.D. blocks of North 24 Parganas in West Bengal, India during period 1987-2020. To figure out the essence of the transition, the supervised classification along with post-classification change detection using the 'From'-'To' approach was employed. Furthermore, hotspot analysis has been utilized to identify all of the areas that are the most variable in terms of change potentiality. Besides, cellular automata were also introduced to find out the character of urban growth and future trend of LULC change. The results show that between 1987 and 2020, agricultural area and vegetation with settlement decreased by $-11.60 \%$ and $-4.34 \%$, respectively, while dense settlement increased by $+15.69 \%$ due to significant population growth and overcrowding from neighboring countries. The prediction model also supports this argument. So, the very high and uncontrolled growth of urban settlement in the study area, may become a big challenge for the district authority to control the unplanned urban expansion.
\end{abstract}

\section{INTRODUCTION}

Human research on the global environment as well as on Landuse-Landcover (LULC) change detection began decades ago (Lambin et al., 2003). Although landuse and landcover are two different terms and distinct in nature (Barnsley et al., 2001), they are often used almost interchangeably (Comber et al., 2008; Kuldeep \& Kamlesh, 2011; Liping et al., 2018; Rawat \& Kumar, 2015). Landcover refers to a region's natural coverage in terms of forest, hilly areas, rivers, oceans, barren land, etc., where there is no role of humans to play in their development. Landuse, on the other hand, refers to human interference with the natural state of the surface of the earth, i.e., how humans utilize the land of nature (Prasad \& Ramesh, 2018). The skinnier of LULC of a specific area determines the physical and socio-economic factors of the respective area and their exploitation in respect of space and time (Rawat \& Kumar, 2015). In recent years, anthropogenic activities have been the leading factor in defining the pattern of land use (Rai, 2017). Nonetheless, this is nothing new. Some of the economically important man-made alterations, including cultivation in different forms by changing the forest cover, reservoir development by reducing the ecological balance of any hilly area, settlement construction by altering the forest as well as barren cover, livestock grazing and so on, has modified the earth surface from the early age of civilization (Turner et al., 1994). The Centre for Geographic Information and Analysis (CGIA) of USA has classified the entire LULC into 7 major classes, 16 subclass, 28 mini classes, and 10 micro classes in Landcover categories and 7 major classes, 25 subclass, 65 mini classes and 179 micro classes in landuse categories. The gradual rise in population concentration and subsequent urban expansion, industrial growth, and development in mining industry since 18th century have greatly influence the landuse and landcover (Riebsame et al., 1994; Sharma et al., 2007) and at the same time, have affect the temperature budget of the urban areas (Ha et al., 2018; Voogt \& Oke, 2003). So, the magnitude, scale and rate of human interference of earth's natural characteristics are unprecedented (Lambin et al., 2001; Turner et al., 1994).

Change detection is a method to identify the modification of the attributes of an object or phenomena of a particular area during a certain time (Amaral et al., 2013; 
Singh, 1989). Change detection analysis can be formulated either by primary field survey and mapping at consecutive times or by comparing temporal datasets, normally two satellite image or aerial photograph at different times (Wang \& Xu, 2010). However, primary field survey-oriented studies are itself not very sufficient and accurate to quantify and analyze the spatio-temporal variation of LULC at a macro level study (Wood \& Skole, 1998). Furthermore, it is not possible to accurately predict the future pattern of change through field observation alone. On the other hand, if the accuracy of the map obtained from remote sensing data is not assessed, it is also worthless (Congalton, 2001). So, the map obtained through remote sensing data and the verification of that map by field-based ground truthing -these two makes a systematic method for any change detection analysis (Cai et al., 2018). Thus, change detection analysis is important and essential for acquiring a very good understanding of the bi-directional interaction as well as relationship between natural occurrences and landscape dynamism. This understanding is essential for the proper resource management and as such various organizations like state, regional, local government, and private corporations use this information for a variety of purposes (Chowdhury et al., 2018; Ha et al., 2018; Hussain et al., 2013; Lu et al., 2004; Petit et al., 2001).

In modern day, the collaboration of remote sensing and geographical Information System (GIS) has an improved and detailed way that makes an easy and intelligible method to map LULC of any location (Selcuk et al., 2003). Currently, the most widely used change detections from the Geographical point of view are change in forest cover and health, spatio-temporal transformation of different coastlines, change along the longitudinal and cross-sectional profile of a river, urban expansion, seasonal productivity of agricultural land, etc. Among them change detection on the urban encroachment into other LULC is predominant. A number of research work have been published around the world from mid 1980s regrading urban encroachment into surrounding organic areas and consequent reduction of agricultural land, filling of wetlands, etc. (Chaurasia et al., 1996; Dewan \& Yamaguchi, 2009; Fortin, 2003; Kushwaha, 1990; Stauffer \& McKinney, 1978).

In present day numerous techniques and algorithms have been established to detect the change among different phenomenon, which in turn have increased the use of remotely sensed data in academic level to predict the future of LULC (Butt et al., 2015). Civco et al. (2002) had examined some popular change detection methods viz. a) traditional post-classification b) cross-tabulation c) cross-correlation analysis d) neural networks e) knowledge-based expert systems and f) image segmentation and object-oriented classification keeping in consideration of seven LULC classes. Their result revealed that the detection of change in each method have some similarities, though a huge difference was also there. They conclude that there is no such single method which can be used without justification. Although they have some confidence on some improved methodology like image-segmentation and rule-based classification. Besides, a compact discussion on various updated image classification technique and associated change detection methods has been summarized in Bhatta (2018), Canty (2014), Jensen (2015). Furthermore, a number of updated change detection method has also been used using binary based change recognition including different image differencing and ratioing like different indices (like NDVI, EVI, MSAVI, NDMI), Principal Component Analysis (PCA) and differencing, Change Vector Analysis (CVA), etc. (Coppin \& Bauer, 1996; Gong et al., 1992; Im et al., 2007; Kefalas et al., 2018; Singh, 1989). So, it is clear that there are two broad type of change detection technique1) category one, which detect the change and reveal a detailed trajectory and 2) category two, binary based change detection which uses Change or No Change technique. Though, the former focuses on a 'From'- 'To' approach which makes a more detailed change interface, while from the later one, anyone can not perceive that what kind of landuse has changed from what kind of landcover and vice versa (Lu et al., 2004; Lu et al., 2005).

North 24 Parganas is a one of the most populated administrative districts in southern West Bengal, of eastern India, was actually the northern part of undivided 24 Parganas district (divided in 1983, 1 March) of several legendary kingdom as well as British ruled West Bengal. The major part of this district lies within the limit of Moribund part of Gangetic delta, are flat and little elevated above the sea level, configured its physical characteristics are common to any deltaic land. Besides, the position of three major rivers namely Bidyadhari, Ichhamati and Yamuna have made the district favorable for agriculture through enormous deposition of silt up to mid-20th century (Bagchi, 1944; Majumdar, 1942; Mukherjee, 1938; O'Malley, 1917) and the position of Hugli river to the far west increases the potentiality for industry-are the major factor of population growth as well as LULC change in this region. However, the former three rivers have become dilapidated either due to excessive siltation or due to conversion of the river course into aquaculture fisheries through damming the flow of the river. Habra I and II blocks are in nearly the central part of the district having a population density of $1918 / \mathrm{km}^{2}$ and $1566 / \mathrm{km}^{2}$ (Handbook, 2011).

A number of Change detection work have been finished on different parts of North 24 Parganas District. Bhattacharjee \& Hazra (2014) have highlighted the regional growth of urban body of Barasat town (district head quarter of North 24 Parganas) as well as its impact on environment in terms of Urban Heat Island (UHI) with the help of Landsat ETM+ image. Basu \& Saha (2017) also have tried to outlined the rate of urbanization in Barasat town. Dhar et al. (2019), on the other hand, has done another work of almost the same kind on newly developed Rajarhat block. A different kind of work, relevant with the southern part of North 24 Parganas by Mondal \& Bandyopadhyay (2014), examined the change in aquaculture of Sandeshkhali I and II block during 1990 to 2013. Hazra \& Saradar (2014) have tried to observe the change of LULC along the Bidyadhari basin within the time period 20012008 using Landsat TM and ETM image. At a course scale, Bera \& Das Chatterjee (2019) have tried to examined the LULC change of overall North 24 Parganas district during the time period 1990-2017 using Maximum Likelihood classification technique. Other works related with LULC 
of the district can be found in Mondal et al. (2017), Rahaman (2018), Saritha \& Kumar (2019).

Thus, numerous studies have been conducted in different parts of the district in the recent past, but no detailed and localized study have been done on Habra I and II block in spite of being located in the central most part of the district. Consequently, by using the modern remote sensing data the author started working with the following objectives in mind-1) to explore the change in LULC of Habra I and II block in a quantitative way, and 2) to find out the future trend of LULC change of the area.

\section{MATERIAL AND METHODS}

\subsection{Study Area}

Habra I and II C.D block are two administrative division in Barasat Sadar subdivision of North 24 Parganas district in the Indian state of West Bengal, located between Gaighata CD block and Haringhata CD block in the north, Swarupnagar and Baduria CD block in the east, Deganga and Barasat I CD block in the south, and Amdanga $\mathrm{CD}$ block in the west. The area extends between $22^{\circ} 46^{\prime} 18^{\prime \prime}$ to $22^{\circ} 55^{\prime} 24^{\prime \prime} \mathrm{N}$ and $88^{\circ} 30^{\prime} 30^{\prime \prime}$ to $88^{\circ} 47^{\prime} 30^{\prime \prime} \mathrm{E}$, covered by Survey of India (SOI) topographical sheets no. 79B/9 and 79B/13 (Fig. 1). The Habra-I and Habra-II block occupies a total number of 58 mouzas and 78 mouzas respectively (revenue villages) under Barasat subdivision. The total area of Habra-I is nearly $117.36 \mathrm{~km}^{2}$ while the total area of Habra-II is nearly $112.67 \mathrm{~km}^{2}$. Since the natural and cultural landscape of the two blocks are almost same, and because of their united location even a few years ago, the LULC changes in these blocks have been measured together.

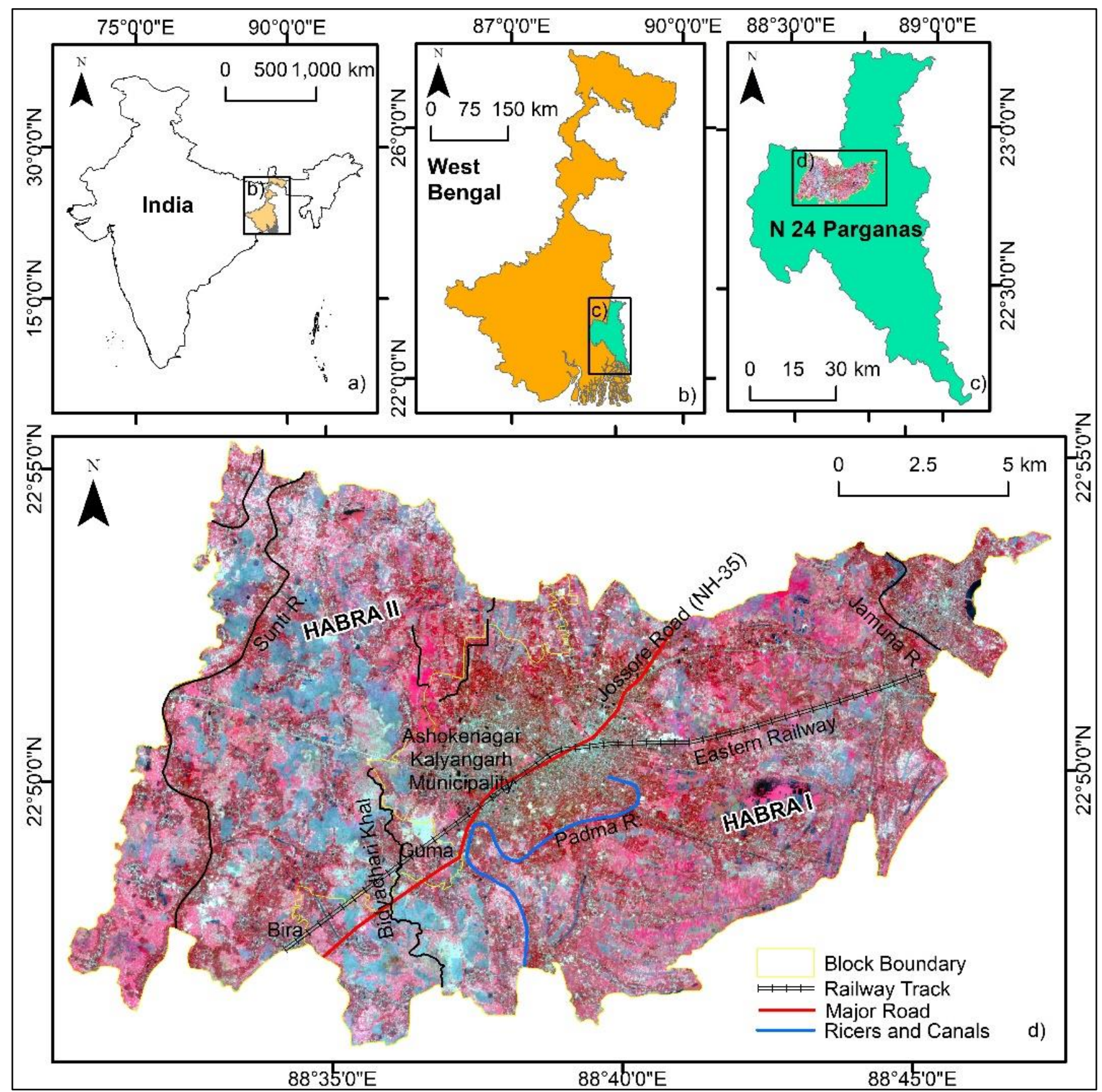

Figure 1. Location map of the study area. in (d) standard FCC has been generated using the red, green, blue and NIR of Landsat image. 


\subsection{Data collection}

The data that are used in this research can be categorized into two independent datasets-a) spaceborne images and b) subsidiary data. It is worth to mentioned that the spaceborne image refers to different multispectral satellite images of different satellite of Landtsat series, whereas subsidiary data refers to topographical sheets, ground truth data, documentary photographs, etc. Satellite data for three different years (1987, 2001, and 2020) comprising of Landsat Thematic Mapper (TM) image, Landsat Enhanced Thematic Mapper (ETM) image, and Landsat Operational Land Imager (OLI) image, were collected from the United States Geological Survey (USGS) Earth Explorer portal (https://earthexplorer.usgs.gov/), to interpret and detect LULC of Habra I and II block. A detailed description of each image is shown in Table 1. Nearly cloud free imagery had been chosen as a major criterion during image selection, because the presence of cloud in the image could pervert the accuracy of image classification work.
Accordingly, we could not take all the imageries for the same month. Although for the convenience of work, the satellite images that have less than 10 percent of cloud had also been accepted. In Indian sub-continent, being a monsoonal affected region, experiences winter season from November to February and the sky remains nearly clear. Thus, imageries from this winter season were the main sources of data for this study assuming that the acquisition period of imageries would have minimal seasonal variation. Besides, ground truth data in the form of reference point, were collected by Garmin hand Global Positioning System (GPS) during the period January, 2020 to February, 2020, used for generating signature file for supervised image classification and subsequent accuracy assessment. A topographical sheet (at a scale of 1:50000) of Survey of India (SOI), surveyed in 1969 , were also collected from self-organizing website of SOI to support the work.

Table 1. Description of all the satellite images used in the study.

\begin{tabular}{ccccccc}
\hline Satellite & Sensor & Path/Row & Date of Acquisition & Band used & Spatial Resolution & Source \\
\hline \multirow{2}{*}{ Landsat-5 } & TM & $138 / 44$ & $24-12-1987$ & Visible (B1, B2, B3) & 30 \\
\multirow{2}{*}{ Landsat-7 } & ETM & \multirow{2}{*}{$138 / 44$} & $26-02-2001$ & NIR (B4) & 30 & 30 \\
Landsat-8 & \multirow{2}{*}{ OLI and TIRS } & \multirow{2}{*}{$138 / 44$} & $12-01-2011$ & NIR (B4) & 30 & USGS \\
& & & $17-01-2020$ & Visible (B2, B3, B4) & 30 \\
\hline
\end{tabular}

Table 2. Description of all the landuse and landcover classes and range of reflectence in terms of DN in that class.

\begin{tabular}{|c|c|c|c|c|c|c|c|}
\hline \multirow{3}{*}{ Sl No. } & \multirow{3}{*}{ Class Name } & \multirow{3}{*}{ Description } & \multicolumn{5}{|c|}{ Range of DN Value } \\
\hline & & & \multirow[b]{2}{*}{ Year } & \multicolumn{4}{|c|}{ Band } \\
\hline & & & & Blue & Green & Red & $\begin{array}{c}\text { Near Infra- } \\
\text { red }\end{array}$ \\
\hline \multirow{3}{*}{1} & \multirow{3}{*}{ Agricultural Land } & \multirow{3}{*}{$\begin{array}{l}\text { Crop fields, nurseries, } \\
\text { floricultural areas and } \\
\text { current fallow lands }\end{array}$} & 1987 & $80-134$ & $65-127$ & $57-142$ & $45-122$ \\
\hline & & & 2001 & $91-136$ & $75-131$ & $61-147$ & $45-122$ \\
\hline & & & 2020 & $90-135$ & $69-127$ & $61-149$ & $45-126$ \\
\hline \multirow{3}{*}{2} & \multirow{3}{*}{$\begin{array}{l}\text { Vegetation with } \\
\text { Settlement }\end{array}$} & \multirow{3}{*}{$\begin{array}{c}\text { plantation, mixture of } \\
\text { vegetation and settle- } \\
\text { ment }\end{array}$} & 1987 & $87-116$ & $69-100$ & $58-113$ & $38-107$ \\
\hline & & & 2001 & $89-110$ & $70-99$ & $56-101$ & $50-104$ \\
\hline & & & 2020 & $89-112$ & $70-102$ & $59-102$ & $66-106$ \\
\hline \multirow{3}{*}{3} & \multirow{3}{*}{ Dense Settlement } & \multirow{3}{*}{$\begin{array}{c}\text { Urban and rural } \\
\text { crowded buildings, } \\
\text { road network, indust- } \\
\text { rial zone }\end{array}$} & 1987 & $99-116$ & 78-99 & $74-107$ & $56-77$ \\
\hline & & & 2001 & $95-118$ & $75-99$ & $72-109$ & $56-82$ \\
\hline & & & 2020 & $90-121$ & $71-108$ & $61-119$ & $47-107$ \\
\hline \multirow{3}{*}{4} & \multirow{3}{*}{ Waterbody } & \multirow{3}{*}{$\begin{array}{l}\text { River, canals, lakes, } \\
\text { ponds }\end{array}$} & 1987 & 88-109 & $66-96$ & $55-110$ & $33-120$ \\
\hline & & & 2001 & $87-108$ & $65-94$ & $55-92$ & $32-88$ \\
\hline & & & 2020 & $92-109$ & $68-99$ & $58-98$ & $33-109$ \\
\hline
\end{tabular}

\subsection{Pre-processing and Image classification}

The downloaded images were imported in ArcGIS 10.6 and composite band tool from data management toolbox was used to stack the useful bands of the image to convert the individual bands into a single file and generate the FCC for the study area. The actual Area of Interest (AOI) of stacked images were then extracted by a georeferenced vector polygon layer of Habra I and II block boundary through the process of clipping. After that the extracted images were exported to Erdas Imagine 2016 for the atmospheric correction (Haze and Noise reduction) and then the corrected images were again imported in ArcGIS 10.6 environment to complete the rest of the work. It is worth to mention that since each AOI was completely free from cloud as well as of nadir view, no cloud removal process and orthorectification was required. Thus, initially all the satellite images were studied through visual interpretation and delineated four classes depending on the characteristics of an image like shape, 
size, tone, texture, association and site. For each predetermined LULC class, polygons were drawn to extract the training samples around the representative sites with the support of the ground truth verification data, high resolution satellite image of Google Earth Pro and topographical sheet of the study area. An acceptable spectral signature must be obtained from that site that ensuring there is 'minimal confusion' among the LULC to be classified. An average of more than 25000 pixels were recorded to create the signature file for each image classification. Therefore, supervised image classification was conducted based on the maximum likelihood algorithm. There were four classes were categorized viz. agricultural land, vegetation with settlement, dense settlement, and waterbody (Table 2). The prime problem during training sample collection was to differentiate between actual vegetation and settlements that are surrounded by vegetation. For this reason, these two classes were shown together as vegetation with settlement.

\subsection{Post-Classification processing and change detec- tion}

A post classification smoothing and refinement in forms of majority filter and boundary cleaning were ap- plied to enhance the accuracy of classification and to reduce the misclassified solitude parts. Thereafter, a postclassification change detection was employed to understand the modification of LULC taking the benefit of "From, -To" approach. To do this, the selected classified images (1987, 2001, and 2020) were converted from raster to polygon layer and then intersected on the basis of a common id of each LULC class. Thus, a change detection was then done by adding a new field in attributes and then keeping the information of each polygon characterized by both of its previous and present LULC class side by side. Finally, four change detection maps-1) change in agricultural area 2) change in vegetation 3 ) change in settlement area and 4) change in waterbody were generated using Eq. (1).

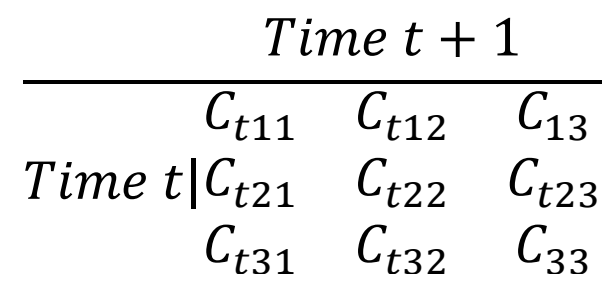

Which means

$$
\text { Time } t+1
$$

(Gross Loss)

\begin{tabular}{r|ccc|c}
\hline Time $t \mid$ & $N C_{1}$ & $\frac{C_{t 12}}{\sum_{i=1}^{3} \sum_{j=1}^{3} C_{t i j}}$ & $\frac{C_{t 13}}{\sum_{i=1}^{3} \sum_{j=1}^{3} C_{t i j}}$ & $\frac{C_{t 12}+C_{t 13}}{\sum_{i=1}^{3} \sum_{j=1}^{3} C_{t i j}}$ \\
& $\frac{C_{t 21}}{\sum_{i=1}^{3} \sum_{j=1}^{3} C_{t i j}}$ & $N C_{2}$ & $\frac{C_{t 23}}{\sum_{i=1}^{3} \sum_{j=1}^{3} C_{t i j}}$ & $\frac{C_{t 21}+C_{t 23}}{\sum_{i=1}^{3} \sum_{j=1}^{3} C_{t i j}}$ \\
& $\frac{C_{t 31}}{\sum_{i=1}^{3} \sum_{j=1}^{3} C_{t i j}}$ & $\frac{C_{t 32}}{\sum_{i=1}^{3} \sum_{j=1}^{3} C_{t i j}}$ & $N C_{3}$ & $\frac{C_{t 31}+C_{t 32}}{\sum_{i=1}^{3} \sum_{j=1}^{3} C_{t i j}}$ \\
\hline Gross Gain in each $\frac{C_{t 21}+C_{t 31}}{\sum_{i=1}^{3} \sum_{j=1}^{3} C_{t i j}}$ & $\frac{C_{t 12}+C_{t 32}}{\sum_{i=1}^{3} \sum_{j=1}^{3} C_{t i j}}$ & $\frac{C_{t 13}+C_{t 23}}{\sum_{i=1}^{3} \sum_{j=1}^{3} C_{t i j}}$ & $\sum_{i=1}^{3}\left[\left(\sum_{i=1}^{3} C_{t i j}\right)-C_{t i j}\right]$
\end{tabular}

Here, in raw transition matrix for three categories, the transitions from category $i$ at time $t$ to category $j$ at time $t+1$ is represented by $c_{i j}$. The right-most column of the Flow matrix gives the gross losses of each category, while the bottom row gives the gross gains. $N C_{1}, N C_{2}$, and $N C_{3}$ are the cells that were not changed during time interval $t$ and $t+1$.

\subsection{Accuracy assessment of classified image}

Accuracy assessment refers to the number of pixels in a classified image that is consistent with the reality, explicitly, how many have been accurately classified using the algorithm. It is very significant for understanding the exactness of the results and use in enforcing various policies (Lu et al., 2004). In this study, accuracy assessment of the classified image was carried out using a total number of 160 ground truth data (40 in each class), obtained from the actual field by the means of random sampling. A confusion matrix was used here (classification result is given in rows while reference is shown in column) because of its popularity and simplicity in the ground of remote sensing. The confusion matrix appears to deliver an excellent summary of the two types of thematic error that can occur, namely, underestimation or omission and overestimation or commission (Foody, 2002). Depending on the information obtained from the contingency table, a number of analytical measures viz. overall accuracy, producer's accuracy, and user's accuracy have been used to calculate the classification accuracy from different perspectives (Richards, 1996; Stehman, 1997). The commission error of any generic class $X 1$ occurs when the classifier assigns some pixels as $X 1$ which do not fit to that class according to the reference data, i.e., number of pixels erroneously assigned, found in off-diagonal elements in each row. Omission on the other hand, is the percentage of pixels situated in a class $X 1$ in the verification or reference data, but have not been assigned in classified image, i.e., the off-diagonal elements in each column are those samples being omitted by the classifier (Bhatta, 2018; Boschetti et al., 2004). Besides, Kappa statistics of the classified image was also performed along with the overall accuracy to enhance the degree of acceptance of the result. The formula of kappa statistics $\mathrm{K}$ is as follows

$$
k=\frac{N \sum_{i=1}^{r} x i i-\sum_{i=1}^{r} x_{i}+* x_{i}+i}{N^{2}-\sum_{i=1}^{r} x_{i}+* x_{i}+i}
$$


The perfect agreement of $K$ is represented when the kappa value is +1 , while a value of 0 represents no agreement (Ha et al., 2018).

\subsection{Measurement of rate and speed of landuse dy- namics}

The rate of land use transition represents the magnitude of the change in land use in the study area over a given time span. This measurement of the dynamicity of LULC either can be measured by single dynamic degree (SDD), or by a comprehensive dynamic degree (CDD) (Jing \& Yue, 2016; Xiao et al., 2012; Yi et al., 2013). The single dynamic degree describes the rate of change in spatial/regional land use, while the comprehensive dynamic degree is determined on the basis of the sum of the single land use dynamics, which quantifies the rate of transformation of the total land use categories and their relationship during the study period (Bera \& Das Chatterjee, 2019; Wang et al., 2001). In this study, the author has followed both of these approaches. The formula for calculating SDD and CDD are described in Eq. (3) and (4).

$$
\begin{gathered}
S_{1}=\frac{L A_{(i, t 1)}-L B_{1}}{L A_{(i, t 1)}} \times \frac{1}{t_{2}-t_{1}} \times 100 \% \\
S_{2}=\frac{\sum_{i=1}^{n}\left\{L A_{(i, t 1)}-L B_{1}\right\}}{\sum_{i=1}^{n} L A_{(i, t 1)}} \times \frac{1}{t_{2}-t_{1}} \times 100 \%
\end{gathered}
$$

Where, $S_{1}$ and $S_{2}$ are single landuse dynamic degree and comprehensive landuse dynamic degree respectively, $L A(i, t 1)$ is the area of a certain type of land use in previous time, $L B_{1}$ is the area of a certain type of land use at a later time, $t_{2}$ and $t_{1}$ are the time of study period, $n$ is the number of landuse landcover classes.

In addition to this, the land use dynamic degree (the rate of change) given by Liu \& He (2002), was also employed to compare the differences between SDD and CDD, following Eq. (5, 6, and 7).

$$
\begin{gathered}
X_{1}=\frac{L A_{(i, t 1)}-N C_{1}}{L A_{(i, t 1)}} \times \frac{1}{t 2-t 1} \times 100 \% \\
X_{2}=\frac{L A_{(i, t 2)}-N C_{1}}{L A_{(i, t 1)}} \times \frac{1}{t 2-t 1} \times 100 \% \\
S C D I=X_{1}+X_{2}
\end{gathered}
$$

Where, $X_{1}$ and $X_{2}$ are the transfer out rate and transfer in rate respectively, $S C D I$ is the spatial-based land use dynamic degree, $L A_{(i, t 2)}$ is the area of a certain type of land use at a later time, $N C_{1}$ is the area that is not changed during the study period.

\subsection{Spatial Change Hotspot Analysis}

In the current review, hotspots were identified as areas with a high density of land cover transition in space. This scientific analysis compares the distribution of attributes to a hypothetical random distribution and helps to define spatial characteristics of the information (Mitchell \& Minami, 1999). Thus, in order to explain the statistical measurement of land-use dynamics around the Habra I and II block, the $\mathrm{G}_{\mathrm{i}}{ }^{*}$ statistics has been used in this article. Integrated Hotspot Analysis tool in ArcGIS determines statistically significant high-value (hotspot) and low-value spatial clusters (coldspots). To complete the work, 750 sample points were randomly generated by creating a random point tool and then attributed using the dynamic degree of LULC change (\% value) in ArcGIS 10.6 software for the entire study area. Hotspot analysis involves each raster pixel in the sense of the adjacent features in the estimation and produces a new vector with z-score, p-value and confidence level. Areas with a high $\mathrm{z}$-score and a low p-value (represent clusters that are, on average, greater than the mean) demonstrate statistically significant hotspots, and areas with a low negative $\mathrm{z}$-score and a small p-value (represent clusters that are less than the mean) reveal statistically significant cold spots (Getis \& Ord, 1996). The formula for calculating the $\mathrm{G}_{\mathrm{i}}^{*}$ are as follows

$$
\begin{gathered}
G_{i}^{*}=\frac{\sum_{j=1}^{n} w_{i} x_{j}-\bar{x} \sum_{j=1}^{n} w_{i j}}{s \sqrt{\left[n \sum_{j=1}^{n} w_{i j}^{2}-\left(\sum_{j=1}^{n} w_{i j}\right)^{2}\right]}} \\
\bar{x}=\frac{n \sum_{j=1}^{n} x j}{n} \\
S=\sqrt{\frac{\sum_{j=1}^{n} x_{j}^{2}}{n}(\bar{x})^{2}}
\end{gathered}
$$

Where, $G_{i}{ }^{*}$ is a $Z$ score, $x j$ is the attribute value for feature $j, w_{i j}$ is the spatial weight between feature $i$ and $j, n$ is equal to the total number of LULC classes. Here, if the distance from a neighbor $j$ to the feature $i$ is within the distance, $w i j=1$, otherwise $w i j=0$.

Hot and cold spots were classified into seven categories based on their $G_{i}$ Bin values: very hot spot (99\% significant), hot spot (95\% significant), warm spot $(90 \%$ significant), not statistically significant, cool spot $(90 \%$ significant), cold spot (95\% significant), and very cold spot (99\% significant). Finally, IDW interpolation method was employed based on the $\mathrm{Z}$ score to show the distribution of hot and cold spot throughout the study area for the period 1987-2001, 2001-2020, and 19872020.

\subsection{Cellular Automata Model for future prediction of built-up extension}

In the present analysis, the potential estimation of built-up growth was predicted in open source QGIS 2.16.3 software using the MOLUSCE (Modules for Land Use Change Evaluation) tool that uses the Cellular Automata Model formula. In QGIS, the Cellular Automata (CA) function is Markovian in nature since it relies on the present state of land use but not on the former one (Yatoo et al., 2020). It first modelled the change potential matrix using the Multi-Layer Perceptron-Artificial Neural Network (MLP-ANN) and then forecast possible LULC changes using the CA model. In the CA-ANN collaboration module, the initial pre-processing of the given data into a 
series of independent variables of the land use classes is performed by dummy coding of different categories into variables such as 0 and 1 (Jogun et al., 2019). It also conducts the normalization of factor variables using the linear normalization formula as shown in Eq. (11).

$$
x_{n}=\frac{X-m_{x}}{\sigma_{x}}
$$

Where, $X$ is a variable, $X_{n}$ is normalized variable, $m_{X}$ is mean of $X$ and $\sigma_{X}$ is standard deviation of $X$.

The prediction was based on two types of variables viz. the dependent variables such as past pattern of LULC changes estimated from 2001 to 2011 Landsat images, and the independent variables such as distance to roads, distance from the CBD, slope, and population density of the area. The distance from road and distance from CBD was generated using the Euclidian distance function in ArcMap software, slope was calculated from the Alos Pulser DEM (12.5m), and the population density map was created using the census data of 1991 and 2011. All the variables were used as input to generate transition potential matrix. To define maximum iteration and neighborhood pixel for the model, the maximum iteration was 1000 and neighborhood pixel was 9 cells i.e., 3 $\times 3$ cells.

$$
A_{i, j}^{t}=\left[\begin{array}{ccc}
a_{i-1, j-1}^{(t)} & a_{i-1, j}^{(t)} & a_{i-1, j+1}^{(t)} \\
a_{i, j-1}^{(t)} & a_{i, j}^{(t)} & a_{i, j+1}^{(t)} \\
a_{i+1, j-1}^{(t)} & a_{i+1, j}^{(t)} & a_{i+1, j+1}^{(t)}
\end{array}\right]
$$

Matching the geometry of layers is crucial to ensure that any random pixel $a_{i, j}$ represents the same piece of land in all the raster layers. Finally, the simulated builtup development for 2030 and 2050 was generated. The validation of the CA-ANN model is important; therefore, the CA-ANN model was validated by comparing simulated LULC for 2020 with classified LULC of 2020 using MOLUSCE QGIS validation module.

The overall methodology of the current study is diagrammatically described in Fig. 2.

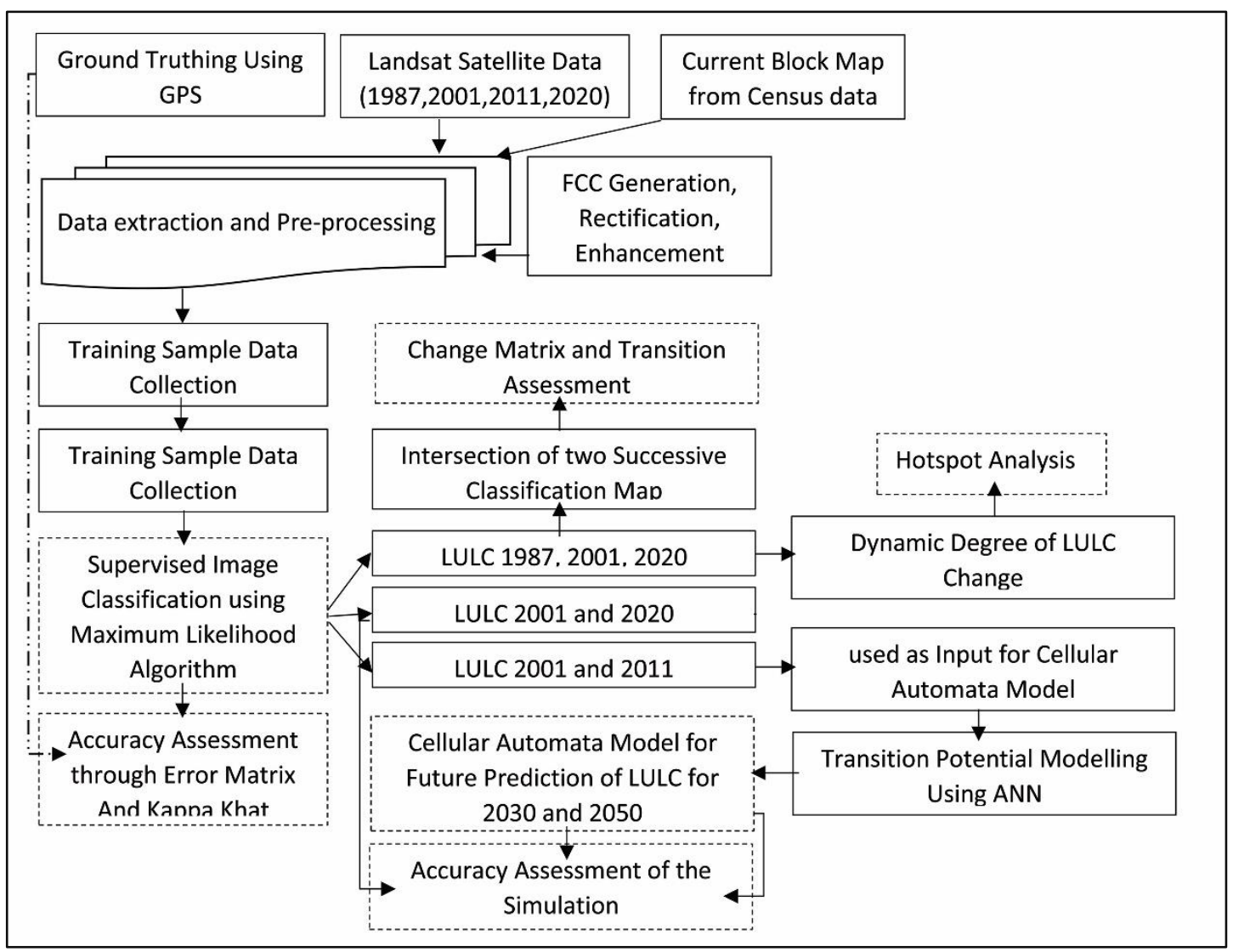

Figure 2. Schematic representation of the methods that were followed in the present study.

\section{RESULT}

\subsection{LULC Status}

The result, obtained from multi-temporal satellite images through supervised LULC classification, covering four major classes viz. agricultural land, vegetation with settlement, dense settlement, and waterbody of the year 1987, 2001, and 2020 are shown in Fig. 3. In addition, the spatial distribution of each LULC class along with the per- centage of the total area occupied by each class is summarized in Table 3. Result demonstrates that in 1987, $59.75 \%\left(168.78 \mathrm{~km}^{2}\right)$ of the total land was under agricultural land, $0.78 \%\left(2.21 \mathrm{~km}^{2}\right)$ under dense settlement, $38.76 \%\left(109.48 \mathrm{~km}^{2}\right)$ of land under vegetation with settlement class, and less than $1 \%\left(1.98 \mathrm{~km}_{2}\right)$ was covered by waterbody. On the other hand, in 2001, 55.23\% area of Habra I and II block (155.96 $\left.\mathrm{km}^{2}\right)$ was covered by agricultural land, $12.91 \%\left(36.46 \mathrm{~km}^{2}\right)$ under dense settlement against $0.78 \%$ in 1987 reveals a sharp increase in 
dense settlement within 14 years. There is a sharp decrease in vegetation with settlement area, which is evident from $30.52 \%\left(86.18 \mathrm{~km}^{2}\right)$ in 2001 instead of $38.76 \%$ in 1987 . In this time waterbody covered $1.33 \%$ (3.76 $\mathrm{km}^{2}$ ) of the total LULC area which portrays a slight increase from the aforementioned period. Results from the classified image of 2020 demonstrates that, nearly $48 \%$ $\left(136.02 \mathrm{~km}^{2}\right)$ of total area was covered by agricultural land, which illustrates a further decrease compared to the 2001. The other classified classes viz dense settlement, vegetation with settlement, and waterbody, covered $16.48 \%$ (46.55 $\mathrm{km}^{2}$ ), $34.42 \%$ (97.24 $\mathrm{km}^{2}$ ), and $0.93 \%\left(2.65 \mathrm{~km}^{2}\right)$ of total land respectively.

\subsection{Net and Overall Change}

The change in different landuse and landcover classes are depicts in Fig. 4. Besides, two change matrices for consecutive decades have also been used to determine the net amount of land encroachment from one LULC class to another during last 33 years. During the period 1987-2001, the net changes (Table 4) are as follow-

a) $10.80 \%$ of agricultural land has been converted into vegetation with settlement, $5.70 \%$ into dense settlement, and $0.83 \%$ area from agricultural land was changed to waterbody. That is, about $82 \%$ of land under agriculture were almost unchanged during this period

b) Nearly $32.27 \%$ of vegetation with settlement area was turn into agricultural land, $18.23 \%$ into dense settlement, and about $1 \%$ land has been converted into waterbody.

c) Almost $9 \%$ of waterbody has been converted into agricultural landuse, $11.56 \%$ towards dense settlement, and about $18 \%$ of waterbody was changed to vegetation with settlement class.

On the other hand, the transformation of different landcover and landuse classes from 2001-2020 (Table 5) is much like this-

a) About $7 \%$ of agricultural land has been converted into dense settlement, $17.77 \%$ of land into settlement with vegetation and $0.30 \%$ of land has been turned into waterbody.

b) During this two decades, about $68.89 \%$ of vegetation with settlement was remain unchanged, but nearly $19 \%$ and $12 \%$ land has been transformed into dense settlement and agricultural landuse, respectively. Besides, $0.48 \%$ area has also been changed to waterbody.

c) $41.77 \%$ area of waterbody has been converted into agricultural land, $14.88 \%$ area into dense settlement, and about $7.78 \%$ area was changed to vegetation with settlement zone.

Thus, after considering each class separately from 1987 to 2020, the overall changes states that a total of $32.76 \mathrm{~km}^{2}$ of agricultural land has been reduced from its actual area, and with it the area of vegetation with settlement has also been reduced from $109.48 \mathrm{~km}^{2}$ in 1987 to $97.24 \mathrm{~km}^{2}$ in 2020 with a net reduction of $12.24 \mathrm{~km}^{2}$. On the contrary, with the decline in these two landuse classes, the area of dense settlement has increased at a proportional rate. Result shows that it has increased from $2.21 \mathrm{~km}^{2}$ in 1987 to $46.55 \mathrm{~km}^{2}$ in 2020 with a net increase of $44.34 \mathrm{~km}^{2}$. Although a net change in waterbody also reveals that there is a net positive change occurred in last 33 years $\left(+0.67 \mathrm{~km}^{2}\right)$.

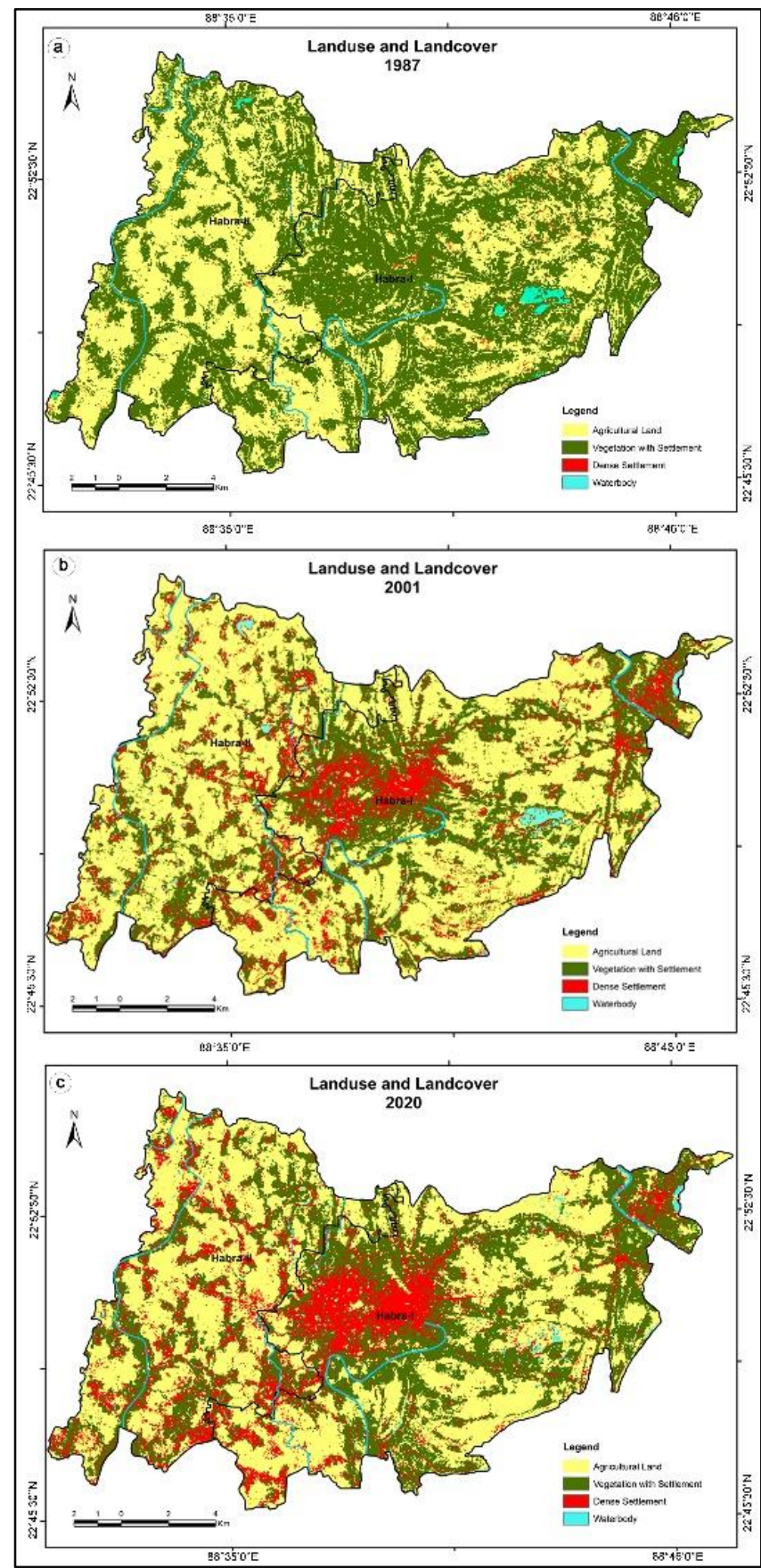

Figure 3. Landuse and Landcover scenario during years 1987, 2001, and 2020 in Habra I and II block (Based on Landsat TM, ETM, and OLI imagery).

\subsection{Accuracy Assessment of classified images}

Overall accuracy, producers' accuracies, users' accuracies, and Kappa coefficient were calculated from the confusion matrix to understand the accuracy of the 2020 image, which is tabulated in Table 6. Accuracy assessment for classified image of 2020 shows that the overall accuracy is equivalent to about 95\%. Producers' accuracies and users' accuracies are also high. As such Producers' accuracies of individual classes are ranging from $92.5 \%$ to $97.5 \%$, while users' accuracies fluctuating between $92.5 \%$ and $100 \%$. The kappa coefficient of the classified image 2020 is about 0.93 . 


\subsection{Change Hotspot analysis}

Spatial autocorrelation is required to know the spatial structure of the LULC data as shown in Fig. 5. The spatial autocorrelation in terms of Moran's I was conducted over three different periods viz. 1987-2001, 2001-2020, and 1987-2020, indicates that the spatial pattern of LULC dynamics is different from case to case. Result demonstrated that the Moran's I value for three different periods is statistically significant. In comparison, the derived $\mathrm{Z}$ score from the spatial autocorrelation indicates that its values are 6.82, 9.83, and 11.80 for 1987-2001, 2001-
2020 and 1987-2020 respectively, suggesting that the distribution is strongly clustered and that there is less than $1 \%$ probability that this clustered trend may be the result of random chance. The hotspot and Coldspot estimates of the Habra I and II blocks, which were computed on three consecutive periods, are presented in Fig. 6 after incorporating Getis-Ord Gi* statistics. Result demonstrates that nearly $13.75 \%$ and $16.12 \%$ area has been categorized as evolving hotspots at more than $90 \%$ confidence level during period 1987-2001 and 2001-2020, respectively,

Table 3. Spatial distribution of each landuse and landcover class and overall change of that class during 1987-2020

\begin{tabular}{|c|c|c|c|c|c|c|c|c|}
\hline & \multicolumn{2}{|l|}{1987} & \multicolumn{2}{|l|}{2001} & \multicolumn{2}{|l|}{2020} & \multicolumn{2}{|c|}{$\begin{array}{l}\text { Overall Change (1987- } \\
2020 \text { ) }\end{array}$} \\
\hline LULC class & Area $\left(\mathrm{km}^{2}\right)$ & $\%$ & Area $\left(\mathrm{km}^{2}\right)$ & $\%$ & Area $\left(\mathrm{km}^{2}\right)$ & $\%$ & Area $\left(\mathrm{km}^{2}\right)$ & $\%$ \\
\hline Waterbody & 1.98 & 0.70 & 3.76 & 1.33 & 2.65 & 0.93 & 0.67 & 0.23 \\
\hline Agricultural Land & 168.78 & 59.75 & 155.96 & 55.23 & 136.02 & 48.15 & -32.76 & -11.60 \\
\hline Vegetation with & 109.48 & 38.76 & 86.18 & 30.52 & 97.24 & 34.42 & -12.24 & -4.34 \\
\hline Settlement & & & & & & & & \\
\hline Dense Settlement & 2.21 & 0.78 & 36.46 & 12.91 & 46.55 & 16.48 & 44.34 & 15.69 \\
\hline
\end{tabular}

Table 4. Landuse and landcover change matrix during 1987-2001

\begin{tabular}{|c|c|c|c|c|c|}
\hline \multirow{6}{*}{ 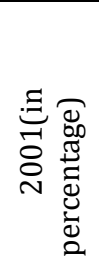 } & \multicolumn{5}{|c|}{1987 (in percentage) } \\
\hline & & Agricultural Land & Dense Settlement & $\begin{array}{c}\text { Vegetation with } \\
\text { Settlement }\end{array}$ & Waterbody \\
\hline & Agricultural Land & 82.66 & 0.00 & 32.27 & 8.99 \\
\hline & Dense Settlement & 5.70 & 100.00 & 18.24 & 11.56 \\
\hline & Vegetation with Settlement & 10.80 & 0.00 & 48.53 & 18.26 \\
\hline & Waterbody & 0.83 & 0.00 & 0.97 & 61.19 \\
\hline & Grand Total & 100.00 & 100.00 & 100.00 & 100.00 \\
\hline
\end{tabular}

Table 5. Landuse and landcover change matrix during 2001-2020

\begin{tabular}{|c|c|c|c|c|c|}
\hline \multirow{7}{*}{ 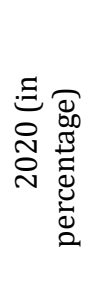 } & \multicolumn{5}{|c|}{2001 (in percentage) } \\
\hline & & $\begin{array}{l}\text { Agricultural } \\
\text { Land }\end{array}$ & Dense Settlement & $\begin{array}{c}\text { Vegetation with } \\
\text { Settlement }\end{array}$ & Waterbody \\
\hline & Agricultural Land & 74.98 & 0.00 & 12.01 & 41.77 \\
\hline & Dense Settlement & 6.96 & 100.00 & 18.62 & 14.88 \\
\hline & Vegetation with Settlement & 17.77 & 0.00 & 68.89 & 7.78 \\
\hline & Waterbody & 0.30 & 0.00 & 0.48 & 35.58 \\
\hline & Grand Total & 100.00 & 100.00 & 100.00 & 100.00 \\
\hline
\end{tabular}

Table 6. Error matrix for accuracy assessment of classified image 2020 with user's accuracy, Producer's accuracy, and kappa coefficient

\begin{tabular}{|c|c|c|c|c|c|c|c|c|}
\hline \multirow{10}{*}{ 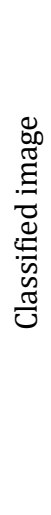 } & \multicolumn{8}{|c|}{ Reference data } \\
\hline & & $\begin{array}{l}\text { Agri- } \\
\text { cultu- } \\
\text { ral } \\
\text { Land }\end{array}$ & $\begin{array}{c}\text { Vegetation } \\
\text { with Settle- } \\
\text { ment }\end{array}$ & $\begin{array}{l}\text { Dense Sett- } \\
\text { lement }\end{array}$ & Waterbody & $\begin{array}{l}\text { Classified } \\
\text { Total }\end{array}$ & $\begin{array}{l}\text { Commis- } \\
\text { sion Error }\end{array}$ & $\begin{array}{c}\text { User's } \\
\text { Accu- } \\
\text { racy }\end{array}$ \\
\hline & Agricultural Land & 37 & 2 & 1 & 0 & 40 & $7.5 \%$ & 92.5 \\
\hline & $\begin{array}{l}\text { Vegetation with Settle- } \\
\text { ment }\end{array}$ & 1 & 38 & 1 & 1 & 41 & $7.32 \%$ & 92.68 \\
\hline & Dense Settlement & 2 & 0 & 38 & 0 & 40 & $5 \%$ & 95 \\
\hline & Waterbody & 0 & 0 & 0 & 39 & 39 & $0 \%$ & 100 \\
\hline & Reference Total & 40 & 40 & 40 & 40 & 160 & & \\
\hline & Omission Error & $7.5 \%$ & $5 \%$ & $5 \%$ & $2.5 \%$ & & & \\
\hline & Producer's Accuracy & $92.5 \%$ & $95 \%$ & $95 \%$ & $97.5 \%$ & & & \\
\hline & Kappa coefficient & 0.93 & & & & & & \\
\hline
\end{tabular}

While in the case of total transition (1987-2020), the proportion of hotspots in the area dropped to 11.06 per cent. Also, most of the hotspots are concentrated in the urban center, along the main road, and near the industrial area. The spatial distribution, on the other hand, shows that during 1987-2001 hotspot regions are clustered in north eastern (Gabardanga municipal area), middle (Habra and Ashokenagar-Kalyangarh municipal area), and in the south-western corner of the block. While, during 2001-2020, former hotspots remained un- 
changed and some new hotspots were introduced adjacent to the Guma, Bira and Joypul CT centers. Notice that according to the LULC attributes, dense settlements have the maximum hotspots, while water bodies have the largest concentration of cold spots. Agricultural land plays the second most important role in the production of cold spots next to the water bodies. The Giz score derived from the hotspot analysis reveals that the distribution of hotspots was more clustered (value ranging from 6.29 to -1.73) during period 1987-2001 than the period 20012020 (value ranging from 5.63 to -3.19 ).

\subsection{Cellular Automata for future trend of LULC change}

The cellular automata simulation method based on the specific landuse change parameters (Fig. 7) was used to detect the changes in the future landuse and landcover in Habra I and II block. In that case, the LULC of 2001 and 2011 has been taken as input to simulate the predicted 2030 and 2050 (Fig. 8). The simulation result indicates that the area under dense settlement will increase from $46.55 \mathrm{~km}^{2}$ in 2020 to about $71.23 \mathrm{~km}^{2}$ in 2030 , and 87.90 $\mathrm{km}^{2}$ in 2050 and most of it will be occupied by residential, industrial, and commercial areas. Side by side, the cumulative area under vegetation with settlement and agricultural land will start decreasing proportionally. According to the simulation result, the vegetation with settlement area will decrease to $85.79 \mathrm{~km}^{2}$ in 2030 and further decrease to $79.23 \mathrm{~km}^{2}$ in 2050 . Similarly, the agricultural land area in 2030 and 2050 will stand at $124.09 \mathrm{~km}^{2}$ and $114.78 \mathrm{~km}^{2}$, respectively which was $136.02 \mathrm{~km}^{2}$ in 2020 .

\subsection{Transition potential modelling using artificial neural network}

Transition Potential Modelling by means of Artificial Neural Network is mandatory before simulating the cellular automata. To do this, $1 \mathrm{px}$ neighborhood, 0.10 learning rate, a maximum iteration of 1000 , and 0.050 momentum was given as inputs to train the CA-ANN model for best result. Result shows that validation Kappa value after ANN was 0.75510 , which is preferably good for simulation (Fig. 9).

\subsection{Prediction Accuracy}

The findings of the CA-ANN system must be checked after simulation using the validation tool of MOLUSCE plugin. In that case, reference map of 2020 and simulation map of 2020 was used as input layer to validate the result. Validation result shows that the overall accuracy is about $83.47 \%$ whereas the kappa value is 0.7823 .

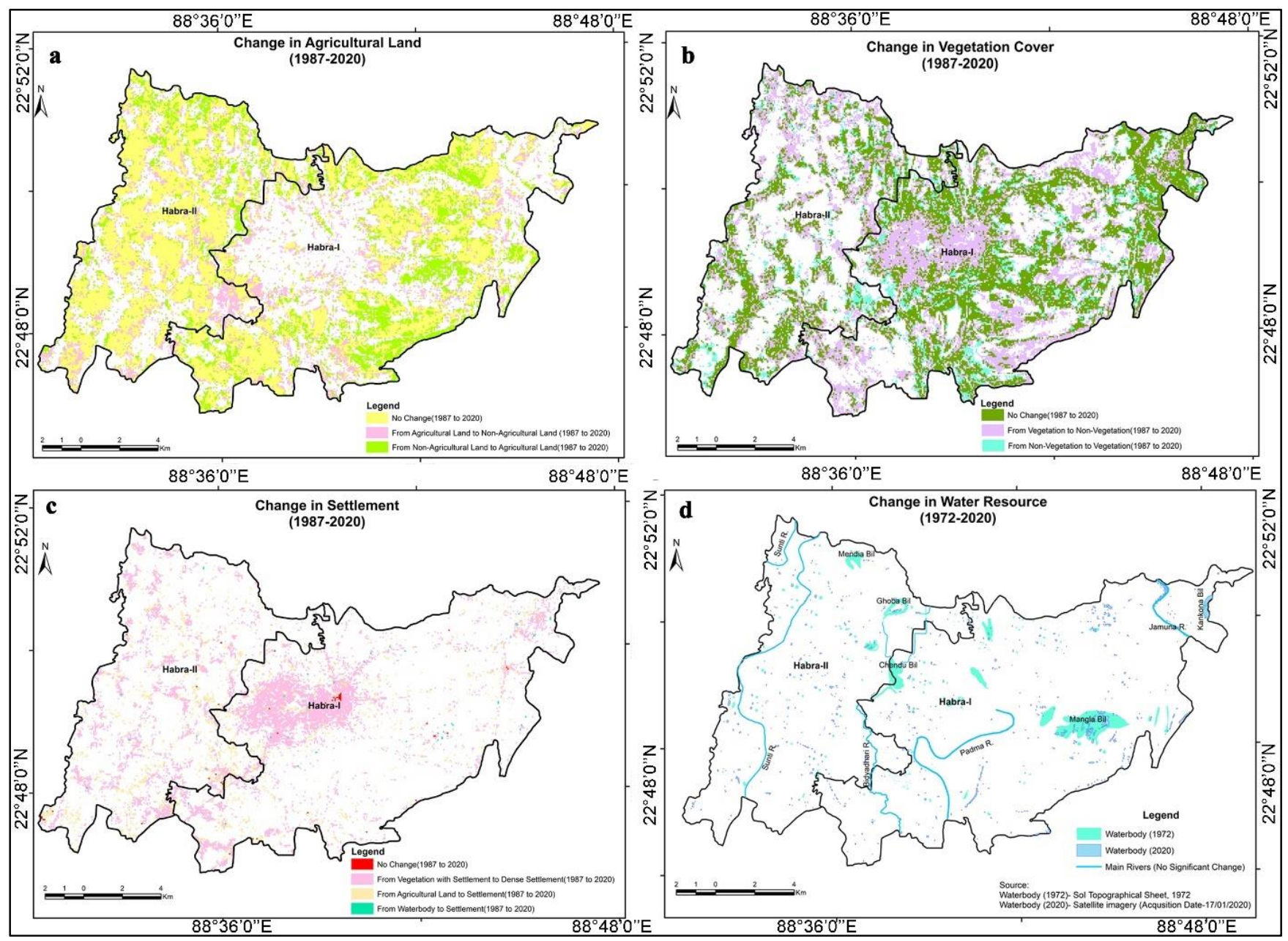

Figure 4. Changing status in Landuse and landcover during 1987-2020. Change in a) agricultural land b) Vegetation cover c) settlement and d) Water resource. 


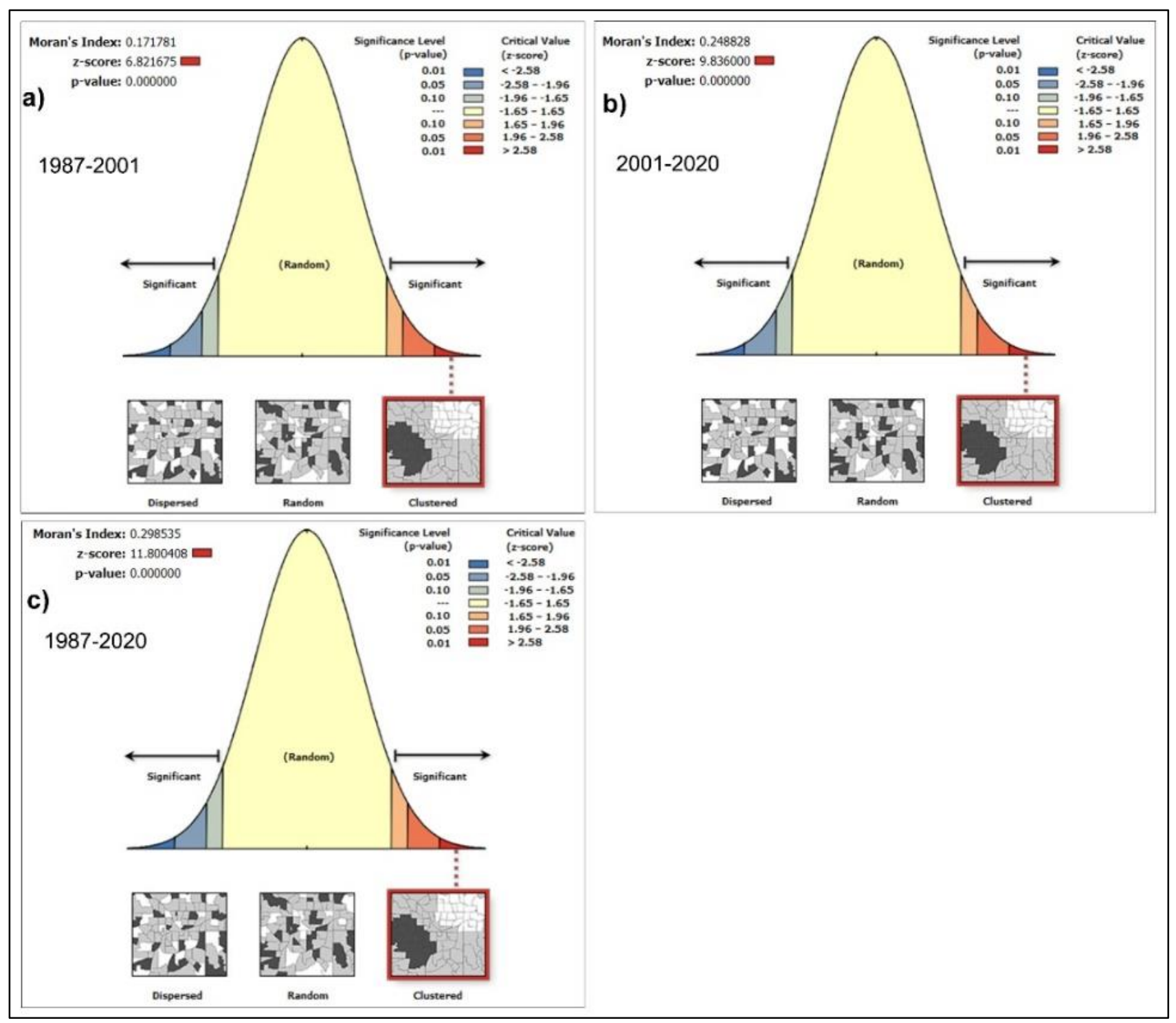

Figure 5. Moran's I significant value, $\mathrm{Z}$ score, and $\mathrm{p}$ value to determine the spatial autocorrelation dur-ing period a)1987-2001 b)2001-2020, and c)1987-2020.

\section{DISCUSSION}

The present research focuses primarily on the spatialtemporal dynamics of land use and land cover transition in the Habra I and II blocks of the North 24 Parganas district and its changing scenario. Now it is clear that the type of LULC did not change parallelly during period 1987-2020, rather at a very fast rate in the first half and then stabilized somewhat. Crowds of refugees from the erstwhile East Pakistan during 1967-1971 due to IndoPakistan war, and after 1985 illegal infiltration from today's Bangladesh (Datta, 2004; Kumar, 2009), can be blamed for the havoc conversion from agricultural and vegetative land to dense settlement. Although, most of the population of these district are concentrated around the Habra, and Ashokenagar-Kalyangarh municipal area (Rahaman, 2018) due to the whole sale business center in Habra which is renowned for selling jute, rice, building materials, cloths, electronic goods, etc., made the area as the second largest wholesale market in West Bengal next to Barabazar in Kolkata (Roy, 2011). Besides, due to the location of the Sealdah-Bangaon branch of the Eastern Railway of India and national highway NH-35 (the Jessore Road), and several other state highways, every portion of these blocks are well connected with the respective municipal town. Therefore, a number of census town has increased in each corner of these municipality by reducing the number of true villages due to household growth, residential progress, commercial influences (viz. industries, tertiary activities), job availability, an increase in the connectivity network, higher educational facility, etc. So, a positive correlation of urban growth can be found between geometric center of the town and distance from major roads and railway station (Majumdar \& Sivaramakrishnan, 2015). Thus, started from the urban center, the trend of urbanization proceeds towards the peripheral zone. 


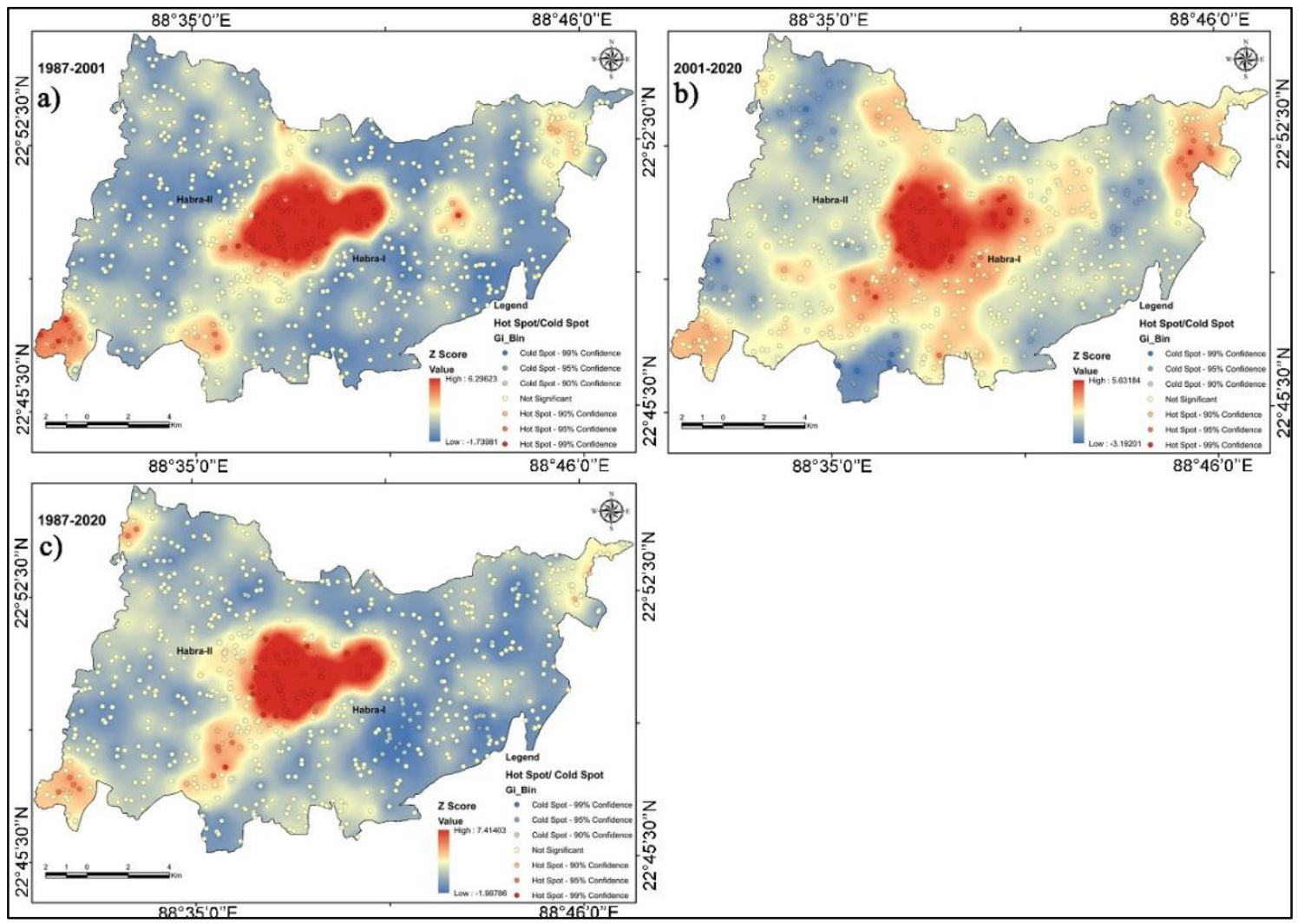

Figure 6. Hot and coldspots, along with the GiZscore variability during a) 1987-2001 b) 2001-2020, and c) 1987-2020.

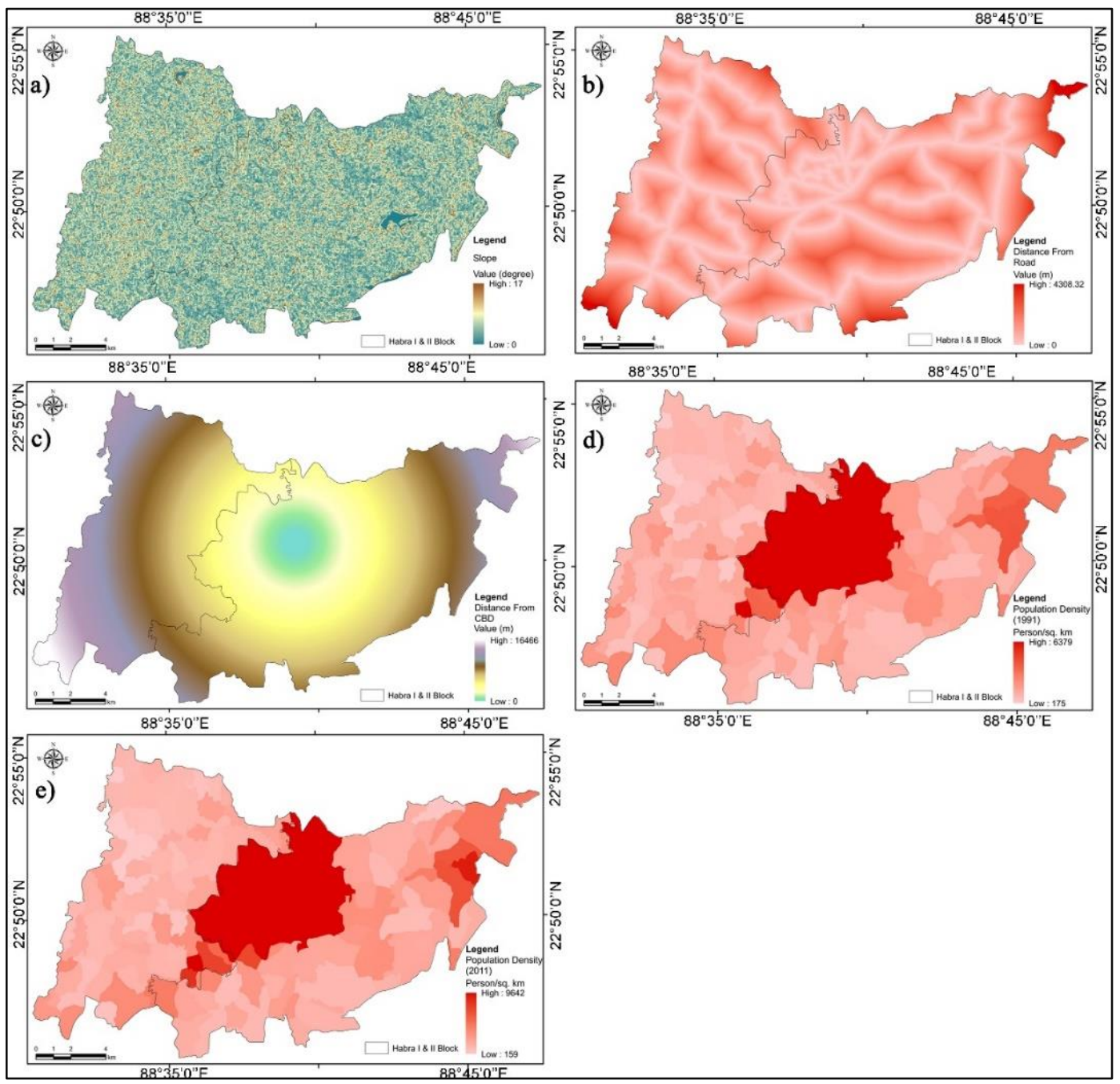

Figure 7. Input factors for the simulation of Cellular Automata Model. Here, a) Slope map b) Distance from the road c) Distance from the CBD d) Population density of 1991, and e) Population density of 2011 
The reason for the steady decline in agricultural land since 1987 can be attributed to the construction of human settlement on the agricultural land. At the same time, the amount of vegetation has also decreased as densely settlements areas have gradually taken over the zones that were characterized by isolated settlements surrounded by trees. Dhali et al. (2019) has evaluated the rate and growth of urban expansion for some selected blocks of the north 24 parganas through Shannon's Entropy Index model and their result demonstrated that the index value increased from 0.21 to 0.78 in Habra-I and increased from 0.23 to 0.67 in Habra-II during period 1989-2016, indicates a high urban growth in last 27 years. Besides, Bera \& Das Chatterjee (2019) also have supported the fastest urbanization of Habra I and II block within North 24 Parganas district and according to them, maximum transformations have taken place from agricultural and vegetation land. On the contrary, the reason for the slight increase in the waterbody area in 2001 as compared to 1987 can be attributed to the flood caused by excessive rainfall in 1999 which had turned the relatively low-lying areas into swamp. Mangla bil, Ghoba bil, Mendia bil, etc. are the perfect example of this occurrence. Besides, by digging ponds on the agricultural land, a lot of new water bodies were created to use the soil as brick material in brick kilns (Bera \& Das Chatterjee, 2019). However, after 2001, the area of waterbody was further reduced either by siltation in the ponds due to disposal of domestic, agricultural and industrial waste (Prabakaran et al., 2013) or by construction of settlements by filling the low-lying areas due to the unusual increase of land price.

It is, therefore, detected that there was an expansion in dense settlement, which could be ascribed to the existing birth and growth rate of the area, infiltration from neighboring countries, development of industrial area etc. Moreover, since the establishment of a commercial drilling station for new oil and gas wells in AshokenagarKalyangarh area by Oil and Natural Gas Corporation (ONGC) after 2020, it is expected that more people will gather in this area (ONGC, 2020) in the near future.

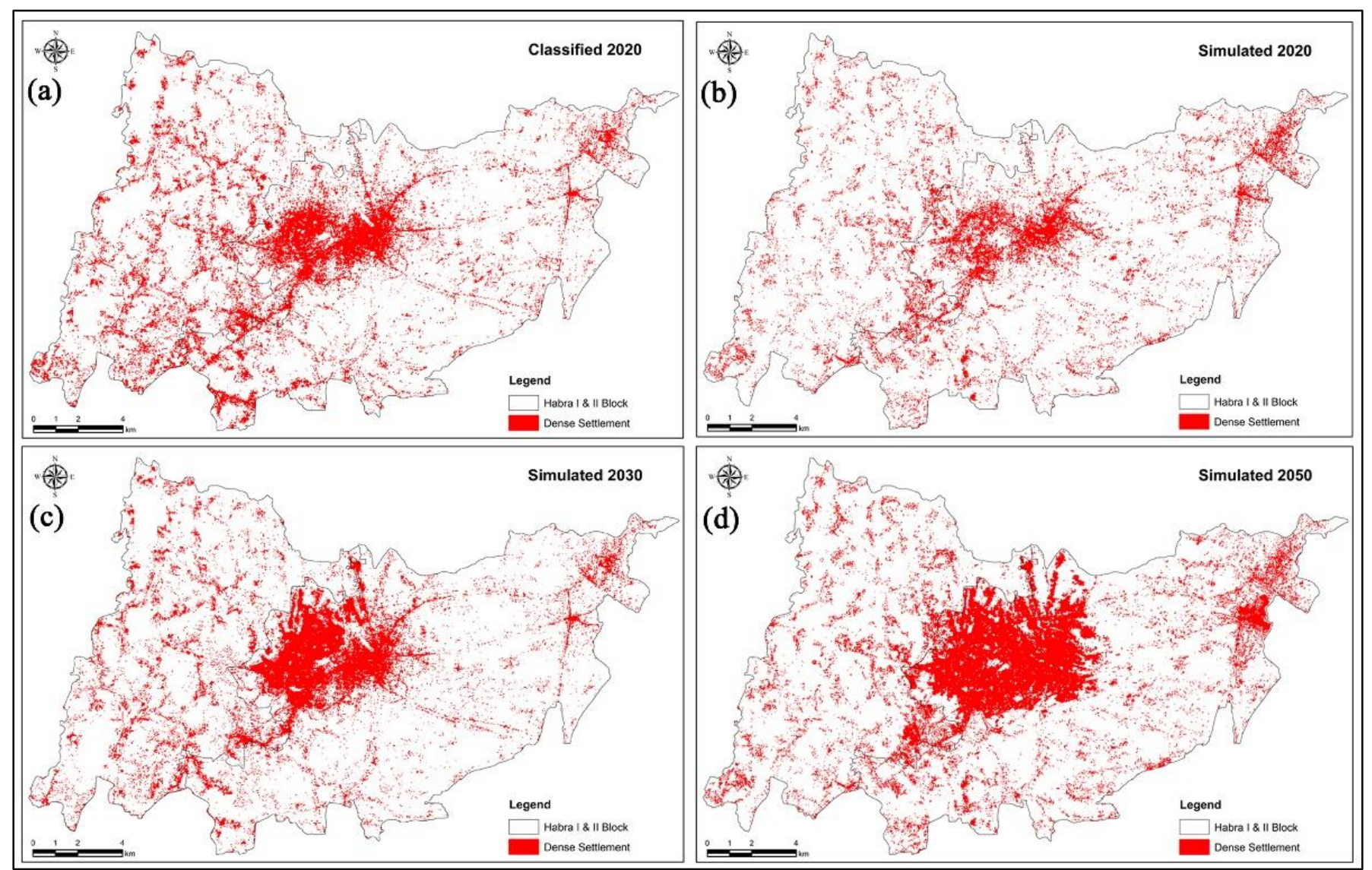

Figure 8. Simulation result from the Cellular Automata showing a) Classified 2020 b) Simulated 2020 c) Simulated 2030, and d) Simulated 2050. 


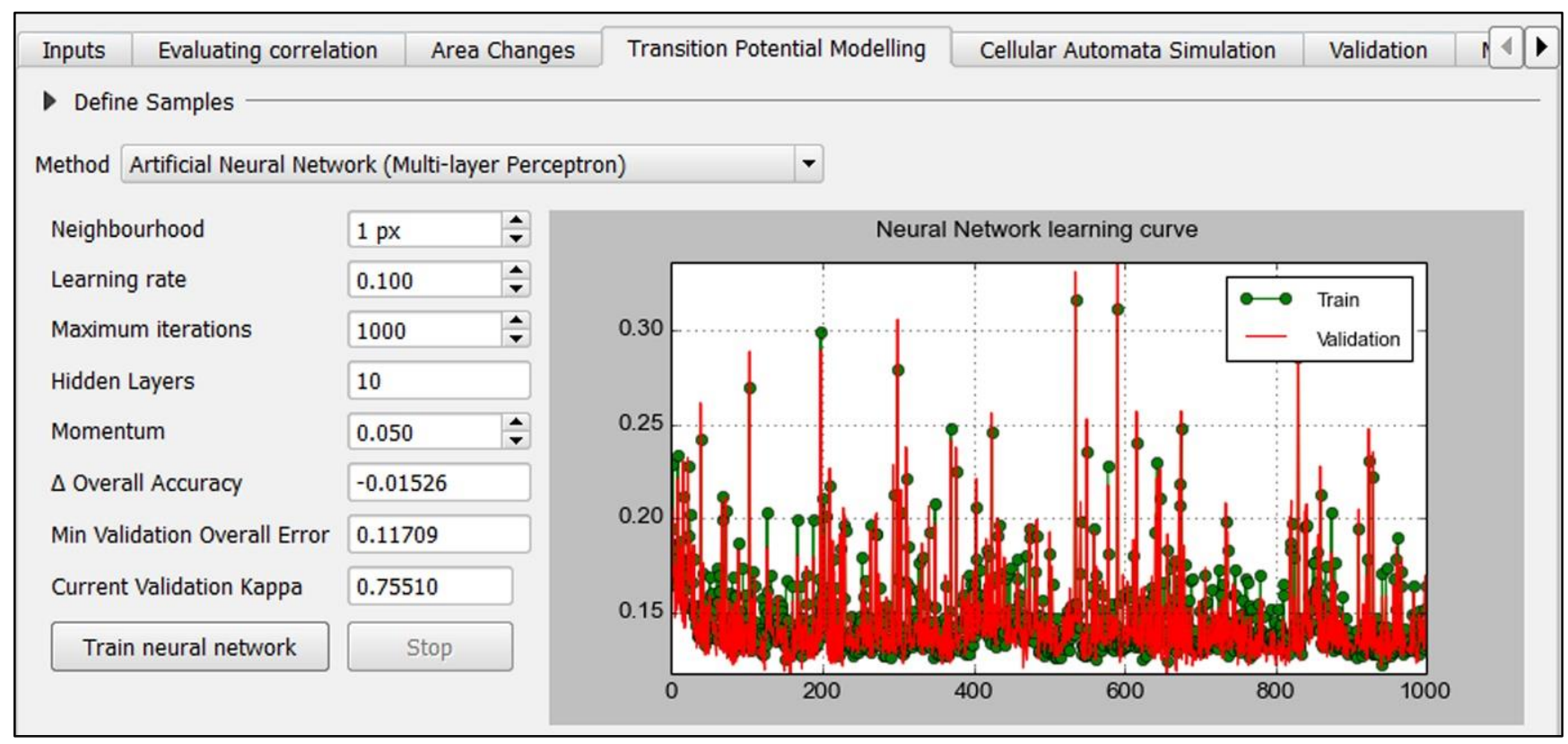

Figure 9. Validation result of the Transition Potential Modelling using ANN.

\section{CONCLUSION}

The present study conducted in one of the populated and developed blocks of North 24 parganas district in West Bengal using a combination of satellite data and GIS to achieve the specific research objectives, advocates the potentiality of remote sensing data over large areas and demonstrates the spatial changes with regard to landuse and landcover information in timely and accurate way for efficient land management and policy decisions. Since, in present day, dense settlement is the principal dynamic part of LULC, but just three decades ago, there was a harmonious balance between agricultural land and vegetation. So, in terms of change matrix, expansion of dense settlement is highest due to the development of small and medium enterprises, proximity to wholesale market, job opportunities, rural-urban migration, and demand for density factor, denotes a clear view of rapid urbanization. Waterbodies, on a contrary, have the lowest rate of spatial change. In other words, a negative correlation exists between urban expansion and all other landuse-landcover classes. Thus, based on the results, it is concluded that the LULC in the study area have transformed from its original condition significantly in past 33 years.

Therefore, although an effective outline of the change in landuse and landcover of Habra I and II block has been summarized through an integration of spaceborne data and subsidiary data, some limitations and uncertainties are also present in this work. Due to the moderate resolution $(30 \mathrm{~m})$ of the Landsat images, it was not possible to perform very fine classification, leaving out very minor objects like small ponds, scatter settlements, etc. In addition, the cover of aquatic vegetation on the streamless rivers, very shallow water, etc., has somewhat reduced the accuracy of the work. Besides, after the termination of the monsoon season, due the lack of rainfall for a prolonged period, the behavior of the agricultural land has become more like an impervious body, which has caused some complications between the agricultural land and the urban area. So, the very high and uncontrolled growth of urban settlement in the study area, may become a big challenge for the district authority to control the unplanned urban expansion. Although, it is very difficult to alter the current system in the already constructed urban body, but some measures like green belt around the urban center, green building, etc. can be adopted to hinder the future effects.

\section{ACKNOWLEDGEMENT}

I am thankful to United States Geological Survey for providing me the Landsat images for free of cost. I would also like to acknowledge all my friends who had helped me in various ways during the fieldwork.

\section{Conflicts of interest}

The authors declare no conflicts of interest.

\section{REFERENCES}

Amaral G, Bushee J, Cordani U G, KAWASHITA K, Reynolds J H, ALMEIDA F F M D E, ... Junho M. do C B (2013). Change detection of urban body. Journal of Petrology, 369(1), 1689-1699. https://doi.org/10.1017/CB09781107415324.004

Bagchi K (1944). The Ganges delta. Calcutta: University of Calcutta.

Barnsley M J, Mollar-Jensen L \& Barr S L (2001). Inferring Urban Land Use by Spatial and Structural Pattern Recognition. In J. P. Donnay, M. J. Barnsley, \& P. A. Longley (Eds.), Remote Sensing and Urban Analysis (pp. 102-130). London: Taylor \& Francis.

Basu T \& Saha S K (2017). The Analysis of Land Use Land Cover Changes Using Geoinformatics and Its Relation to Changing Population Scenariosin Barasat Municipality in North Twenty-Four Parganas, West Bengal. International Journal of Humanities and Social Science Invention, 6(8), 1-13.

Bera S \& Das Chatterjee N (2019). Mapping and monitoring of land use dynamics with their change hotspot in 
North 24-Parganas district, India: a geospatial- and statistical-based approach. Modeling Earth Systems and Environment, 5(4), 1529-1551.

https://doi.org/10.1007/s40808-019-00601-2

Bhatta B (2018). Remote sensing and GIS (2nd ed.). Oxford University Press.

Bhattacharjee D \& Hazra S (2014). Distribution of Land Surface Temperature Over Built-up Area by Web-GIS Techniques. Indian Journal of Spatial Science, 5(2), 70-76.

Boschetti L, Flasse S P \& Brivio P A (2004). Analysis of the conflict between omission and commission in low spatial resolution dichotomic thematic products: The Pareto Boundary. Remote Sensing of Environment, 91(1), 280-292. https://doi.org/10.1016/j.rse.2004.02.015

Butt A, Shabbir R, Ahmad S S \& Aziz N (2015). Land use change mapping and analysis using Remote Sensing and GIS: A case study of Simly watershed, Islamabad, Pakistan. The Egyptian Journal of Remote Sensing and Space, 18(2), 251-259. https://doi.org/10.1016/j.ejrs.2015.07.003

Cai L, Shi W, Miao Z \& Hao M (2018). Accuracy assessment measures for object extraction from remote sensing images. Remote Sensing, 10(2), 303. https://doi.org/10.3390/rs10020303

Canty M J (2014). Image analysis, classification and change detection in remote sensing With Algorithms for ENVI/IDL and Python (3rd ed.). Boca Raton: CRC Press, Taylor \& Francis Group.

Chaurasia R, Loshali D C, Dhaliwal S S, Sharma P K, Kudrat M \& Tiwari A K (1996). Land use change analysis for agricultural management-A case study of Tehsil Talwandi Sabo, Punjab. Journal of the Indian society of remote sensing, 24(2), 115123.https://doi.org/doi.org/10.1007/BF03016124

Chowdhury M, Emran M \& Abdullah-al-mamun M M (2018). Land use/land cover change assessment of Halda watershed using remote sensing and GIS. The Egyptian Journal of Remote Sensing and Space Sciences, 23(1), 63-75.

https://doi.org/10.1016/j.ejrs.2018.11.003

Civco D L, Hurd J D, Wilson E H, Song M \& Zhang Z (2002). A comparison of land use and land cover change detection methods. ASPRS-ACSM Annual Conference and FIG XXII Congress.

Comber A J, Wadsworth R A \& Fisher P F (2008). Using semantics to clarify the conceptual confusion between land cover and land use: the example of 'forest.' Journal of Land Use Science, 3(2-3), 185-198. https://doi.org/10.1080/17474230802434187

Congalton R G (2001). Accuracy assessment and validation of remotely sensed and other spatial information. International Journal of Wildland Fire, 10(3-4), 321328. https://doi.org/10.1071/wf01031

Coppin P R \& Bauer M E (1996). Digital Change Detection in Forest Ecosystems with Remote Sensing Imagery. Remote Sensing Reviews, 13(3-4), 207-234. https://doi.org/https://doi.org/10.1080/02757259 609532305

Datta P (2004). Push-pull factors of documented migration from Bangladesh to west Bengal: a perception study.
Dewan A M \& Yamaguchi Y (2009). Using remote sensing and GIS to detect and monitor land use and land cover change in Dhaka Metropolitan of Bangladesh during 1960 - 2005. Environmental Monitoring and Assessment, 150(1-4), 237-249.

https://doi.org/10.1007/s10661-008-0226-5

Dhali M K, Chakraborty M \& Sahana M (2019). Assessing spatio-temporal growth of urban sub-centre using Shannon's entropy model and principal component analysis: A case from North 24 Parganas, lower Ganga River Basin, India. Egyptian Journal of Remote Sensing and Space Science, 22(1), 25-35.

https://doi.org/10.1016/j.ejrs.2018.02.002

Dhar R B, Chakraborty S, Chattopadhyay R \& Sikdar P K (2019). Impact of Land-Use / Land-Cover Change on Land Surface Temperature Using Satellite Data: A Case Study of Rajarhat Block, North 24-Parganas District, West Bengal. Journal of the Indian Society of Remote Sensing, 47(2), 331-348.

https://doi.org/10.1007/s12524-019-00939-1

Foody G M (2002). Status of land cover classification accuracy assessment. Remote Sensing of Environment, 80(1), 185-201.

https://doi.org/https://doi.org/10.1016/S00344257(01)00295-4

Fortin M (2003). On the role of spatial stochastic models in understanding landscape indices in ecology. Oikos, 102(1), 203-212. https://doi.org/https://doi.org/10.1034/j.16000706.2003.12447.x

Getis A \& Ord J K (1996). Spatial analysis and modeling in a GIS environment. In R. B. McMaster \& E. L. Usery (Eds.), A research agenda for geographic information science (pp. 157-160). CRC Press,Taylor \& Francis Group.

Gong P, Ledrew E F \& Miller J R (1992). Registrationnoise reduction in difference images for change detection. International Journal of Remote Sensing, 13(4), 773-779. https://doi.org/10.1080/01431169208904151

Ha T V, Tuohy M, Irwin M \& Tuan P V (2018). Monitoring and mapping rural urbanization and land use changes using Landsat data in the northeast subtropical region of Vietnam. The Egyptian Journal of Remote Sensing and Space Sciences, 23(1), 11-19. https://doi.org/10.1016/j.ejrs.2018.07.001

Handbook D C (2011). West Bengal.

Hazra S \& Saradar J (2014). Monitoring of landuse and landcover - a case study of Bidyadhari basin, North 24 Parganas, West Bengal. Geographical Review of India.

Hussain M, Chen D, Cheng A, Wei H \& Stanley D (2013). Change detection from remotely sensed images: Frompixel-based to object-based approaches. ISPRS Journal of Photogrammetry and Remote Sensing, 80(1), 91-106. https://doi.org/10.1016/j.isprsjprs.2013.03.006

Im J, Rhee J, Jensen J R \& Hodgson M E (2007). An automated binary change detection model using a calibration approach. Remote Sensing of Environment, 106(1), 89-105. https://doi.org/10.1016/j.rse.2006.07.019

Jensen J R (2015). Introductory digital image processing a Remote Sensing Perspective (4th ed.). 
Jing Y \& Yue Z (2016). Change and prediction of the land use /cover in Ebinur Lake Wetland Nature Reserve based on CA-Markov model. Chinese Journal of Applied Ecology, 27(11), 3649-3658.

https://doi.org/1001-9332.201611.027

Jogun T, Lukić A \& Gašparović M (2019). Simulation model of land cover changes in a post-socialist peripheral rural area: Požega-slavonia county, croatia. Hrvatski Geografski Glasnik, 81(1), 31-59. https://doi.org/10.21861/HGG.2019.81.01.02

Kefalas G, Xofis P, Lorilla R S \& Martinis A (2018). The use of vegetation indices and change detection techniques as a tool for monitoring ecosystem and biodiversity integrity. International Journal of Sustainable Agricultural Management and Informatics, 4(1), 47-67. https://doi.org/10.1504/IJSAMI.2018.10013626

Kuldeep T \& Kamlesh K (2011). Land Use / Land cover change detection in Doon valley (Dehradun Tehsil), Uttarakhand: using GIS \& Remote Sensing Technique. International Journal of Geomatics and Geosciences, 2(1), 34-41.

Kumar C (2009). Migration and refugee issue between India and Bangladesh. Scholar's Voice: A New Way of Thinking, 1(1), 62-84.

Kushwaha S P S (1990). Forest-type mapping and change detection from satellite imagery. Journal of Photogrammetry and Remote Sensing, 45(3), 175-181. https://doi.org/https://doi.org/10.1016/09242716(90)90057-I

Lambin E F, Geist H J \& Lepers E (2003). Dynamics of land-use and land-cover change in tropical regions. Annual Review of Environment and Resources, 28(1), 205-241. https://doi.org/10.1146/annurev.energy.28.050302.105459

Lambin E F, Turner B L, Geist H J, Agbola S B, Angelsen A, Folke C, ... Veldkamp T A (2001). The causes of landuse and land-cover change: moving beyond the myths. Global Environmental Change, 11(4), 261269.

https://doi.org/https://doi.org/10.1016/S09593780(01)00007-3

Liping C, Yujun S \& Saeed S (2018). Monitoring and predicting land use and land cover changes using remote sensing and GIS techniques:A case study of a hilly area, Jiangle, China. PLoS ONE, 13(7), 1-23.

https://doi.org/https://doi.org/10.1371/journal.pone.0200493

Liu S \& He S J (2002). A spatial analysis model for measuring the rate of land use change. Journal of Natural Resources, 17(5), 533-540.

Lu D, Li G, Valladares G S \& Batistella M (2004). Mapping soil erosion risk in Rondônia, Brazilian Amazonia: Using RUSLE, remote sensing and GIS. Land Degradation and Development, 15(5), 499-512. https://doi.org/10.1002/ldr.634

Lu D, Mauselt P, Batistells M \& Moran E (2005). Landcover binary change detection methods for use in the moist tropical region of the Amazon: a comparative study. International Journal of Remote Sensing, 26(1), 101-114. https://doi.org/https://doi.org/10.1080/01431160 410001720748
Majumdar (1942). Rivers of the Bengal delta. University of Calcutta.

Majumdar S \& Sivaramakrishnan L (2015). Patterns of land use in and around Kolkata city: A spatio-temporal analysis. Indian Cartographer, 35, 218-223.

Mitchell A \& Minami M (1999). The ESRI guide to GIS analysis: geographic patterns \& relationships (1st ed.). ESRI, Inc.

Mondal B, Dolui G, Pramanik M, Maity S \& Sarathi S S (2017). Urban expansion and wetland shrinkage estimation using a GIS-based model in the East Kolkata Wetland, India. Ecological Indicators, 83(November 2016), 62-73. https://doi.org/10.1016/j.ecolind.2017.07.037

Mondal I \& Bandyopadhyay J (2014). Studies on the nature of studies on the nature of change in aquaculture through application of remote sensing \& GIS techniques: a case study on Sandeshkhali- i \& ii blocks, North 24 Parganas, West Bengal, India. Indian Cartographer, $34(1)$.

Mukherjee R (1938). The changing face of Bengal-A study in riverine economy. Calcutta: University of Calcutta.

O’Malley L S S (1917). Bengal Bihar Orissa and Sikkim (t. $\mathrm{H}$. Holland, ed.). Cambridge university press.

ONGC (2020). ONGC starts oil and gas production from West Bengal after 60 years endeavor. Financial Express, p. 2.

Petit C, Scudder T \& Lambin E (2001). Quantifying processes of land-cover change by remote sensing: resettlement and rapid land-cover changes in south-eastern Zambia. International Journal of Remote Sensing, 22(17), 3435-3456. https://doi.org/10.1080/01431160010006881

Prabakaran K, Pal R \& Chitra J (2013). Hydrobiological characteristics of Freshwater Habitats of South Dum Dum Municipality, North 24 Parganas District, West Bengal, India. Journal of Academia and Industrial Research (JAIR), 2(3), 3-6.

Prasad G \& Ramesh M V (2018). Spatio-Temporal Analysis of Land Use/Land Cover Changes in an Ecologically Fragile Area-Alappuzha District, Southern Kerala, India. Natural Resources Research, 28(2), 31-42. https://doi.org/10.1007/s11053-018-9419-y

Rahaman M (2018). Urban Population Growth in the Municipalities of North 24 Parganas: A Spatio-Temporal Analysis. World Wide Journal of Mul t Idiscipl Inary Research and Development, 4(3), 68-73.

Rai R (2017). A Synthesis of Studies on Land Use and Land Cover Dynamics during 1930 - 2015 in Bangladesh. Sustainability 2017, 9, 1-20. https://doi.org/10.3390/su9101866

Rawat J S \& Kumar M (2015). Monitoring land use / cover change using remote sensing and GIS techniques: A case study of Hawalbagh block, district Almora , Uttarakhand, India. The Egyptian Journal of Remote Sensing and Space Sciences, 18(1), 77-84. https://doi.org/10.1016/j.ejrs.2015.02.002

Richards J A (1996). Classifier performance and map accuracy. 57(3), 161-166. https://doi.org/https://doi.org/10.1016/00344257(96)00038-7 
Riebsame W E, Meyer W B \& Turner B L (1994). MODELING LAND USE AND COVER AS PART OF GLOBAL ENVIRONMENTAL CHANGE. Climatic Change, 28(10), 45-64. https://doi.org/doi.org/10.1007/BF01094100

Roy T (2011). Nature and dynamism of rural urban continuum of North 24 Parganas with special reference to Barasat town. University of Calcutta.

Saritha S \& Kumar G S (2019). Change detection in urban landscapes: a tensor factorization approach. Patial Information Research, 27(5), 587-600. https://doi.org/doi.org/10.1007/s41324-01900255-3

Selcuk R, Recep N, Bayram U \& Ali Y (2003). Monitoring Land -Use Changes by GIS and Remote Sensing Techniques: Case Study of Trabzon. 2nd FIG Regional Conference, (December 2-5), 1-11.

Sharma R, Xu J \& Sharma G (2007). Traditional agroforestry in the eastern Himalayan region: Land management system supporting ecosystem services. Tropical Ecology, 48(2), 189-200.

Singh A (1989). Digital change detection techniques using remotely-sensed data. International Journal of Remote Sensing, 10(6), 989-1003. https://doi.org/10.1080/01431168908903939

Stauffer M L \& McKinney R L (1978). Landsat image differencing as an automated land cover change detection technique (interim report).

Stehman S V (1997). Selecting and Interpreting Measures of Thematic Classification Accuracy. Remote Sensing of Environment, 62(1), 77-89. https://doi.org/10.1016/S0034-4257(97)00083-7

Turner A B L, Meyer W B \& Skole D L (1994). Global LandUse/Land-Cover Change: Towards an Integrated Study. Ambio: Integrating Earth System Science, 23(1), 91-95.

https://doi.org/https://doi.org/10.2307/4314168
Voogt J A \& Oke T R (2003). Thermal remote sensing of urban climates. Remote Sensing of Environment, 86(3), 370-384. https://doi.org/10.1016/S00344257(03)00079-8

Wang F \& Xu Y (2010). Comparison of remote sensing change detection techniques for assessing hurricane damage to forests. Environmental Monitoring and Assessment, 162(1-4), 311-326. https://doi.org/10.1007/s10661-009-0798-8

Wang J, Fu B, Qiu Y \& Chen L (2001). Soil nutrients in relation to land use and landscape position in the semiarid small catchment on the loess plateau in China. Journal of Arid Environments, 48(4), 537-550. https://doi.org/10.1006/jare.2000.0763

Wood C H \& Skole D (1998). Linking Satellite, Census, and Survey Data to Study Deforestation in the Brazilian Amazon. In D. Liverman, E. F. Moran, \& R. R. Rindfuss (Eds.), People and Pixels, Linking Remote Sensing and Social Science (pp. 70-93). Washington, D.C.: National Academy Press.

Xiao M, Wu J, Chen Q, Jin M \& Zhang Y (2012). Dynamic change of landuse in Changhua downstream watershed based on CA-Marcov model. Transactions of the Chinese Society of Agricultural Engineering, 28(10), 231-238.

Yatoo S A, Sahu P, Kalubarme M H \& Kansara B B (2020). Monitoring land use changes and its future prospects using cellular automata simulation and artificial neural network for Ahmedabad city, India. GeoJournal, 5. https://doi.org/10.1007/s10708-020-10274-5

Yi L, Zhang Z, Wang X, Liu B, Zuo L, Zhao X \& Wang J (2013). Spatial-temporal change of major reserve resources of cultivated land in China in recent 30 years. Transactions of the Chinese Society of Agricultural Engineering, 29(6), 1-12. 